\title{
Human oscillatory activity associated to reward processing in a gambling task
}

\author{
Josep Marco-Pallares ${ }^{\mathrm{a}}$, David Cucurell ${ }^{\mathrm{b}}$, Toni Cunillera ${ }^{\mathrm{b}}$, Rafael García ${ }^{\mathrm{b}}$, \\ Antonio Andrés-Pueyo ${ }^{c}$, Thomas F. Münte ${ }^{\mathrm{a}}$, Antoni Rodríguez-Fornells ${ }^{\mathrm{b}, \mathrm{d}, *}$ \\ a Department of Neuropsychology, Otto von Guericke University, 39112 Magdeburg, Germany \\ ${ }^{\mathrm{b}}$ Department of Basic Psychology, Faculty of Psychology, University of Barcelona, Spain \\ ${ }^{\mathrm{c}}$ Department of Personality, Faculty of Psychology, University of Barcelona, Spain \\ ${ }^{\mathrm{d}}$ Institució Catalana de Recerca i Estudis Avançats (ICREA), Spain
}

Received 25 January 2007; received in revised form 18 July 2007; accepted 19 July 2007

\begin{abstract}
Previous event-related brain potential (ERP) studies have identified a medial frontal negativity (MFN) in response to negative feedback or monetary losses. In contrast, no EEG correlates have been identified related to the processing of monetary gains or positive feedback. This result is puzzling considering the large number of brain regions involved in the processing of rewards. In the present study we used a gambling task to investigate this issue with trial-by-trial wavelet-based time-frequency analysis of the electroencephalographic signal recorded non-invasively in healthy humans. Using this analysis a mediofrontal oscillatory component in the beta range was identified which was associated to monetary gains. In addition, standard time-domain ERP analysis showed an MFN for losses that was associated with an increase in theta power in the time-frequency analysis. We propose that the reward-related beta oscillatory activity signifies the functional coupling of distributed brain regions involved in reward processing. (C) 2007 Elsevier Ltd. All rights reserved.
\end{abstract}

Keywords: Feedback; Gambling; Medial frontal negativity; Reward; Wavelet analysis

\section{Introduction}

In order to successfully navigate through a busy day, we need to constantly assess the values and uncertainties attached to different options and to adapt our behavior according to the outcome of an action which might or might not match our predictions and hopes. The function of positive (rewards) and negative feedback signals (punishments) in this scenario is to guide behavior and to mediate learning (Schultz, 2006). The brain network activated in reward processing comprises the orbitofrontal cortex, amygdala, ventral striatum/nucleus accumbens, prefrontal cortex and anterior cingulate cortex (Delgado, Nystrom, Fissell, Noll, \& Fiez, 2000; Gottfried, O’Doherty, \& Dolan, 2003; Knutson, Fong, Bennett, Adams, \& Hommer,

\footnotetext{
* Corresponding author at: Dept. Psicologia Bàsica, Facultat de Psicologia, Universitat de Barcelona, Passeig de la Vall d'Hebron 171, Barcelona 08035, Spain. Fax: +34 934021363 .

E-mail address: antoni.rodriguez@icrea.es (A. Rodríguez-Fornells).
}

2003; Knutson, Westdorp, Kaiser, \& Hommer, 2000; O’ Doherty, Kringelbach, Rolls, Hornak, \& Andrews, 2001). However, although the neural circuit involved in reward processing is quite well defined, the specific roles of each region and the integration of information in this circuit are not well understood.

Several authors have proposed that in order to integrate a disparate number of different rewards the brain uses a common network that converges in a final pathway that informs about the nature of the reward (comparison process) and about the possible courses of action in the future (Montague \& Berns, 2002; Shizgal, 1997). Neurophysiological studies in animals revealed dopaminergic neurons in the midbrain projecting, among other regions, to the ventral striatum responding selectively to unpredicted events: (i) they are mostly responsive to appetetive events that are better than predicted, (ii) they do not respond to well-predicted rewards, and (iii) a negative signal (i.e. decreased activity) is elicited when an appetetive event is worse than predicted (Mirenowicz \& Schultz, 1994; Schultz, Dayan, \& Montague, 1997; Tremblay \& Schultz, 2000; for similar results in humans: Berns, McClure, Pagnoni, \& Montague, 
Knutson, B., Fong, G. W., Adams, C. M., Varner, J. L., \& Hommer, D. (2001). Dissociation of reward anticipation and outcome with event-related fMRI. Neuroreport, 12, 3683-3687.

Knutson, B., Fong, G. W., Bennett, S. M., Adams, C. M., \& Hommer, D. (2003). A region of mesial prefrontal cortex tracks monetarily rewarding outcomes: Characterization with rapid event-related fMRI. Neuroimage, 18, 263-272.

Knutson, B., Westdorp, A., Kaiser, E., \& Hommer, D. (2000). FMRI visualization of brain activity during a monetary incentive delay task. Neuroimage, 12, 20-27.

LaBar, K. S., Gatenby, J. C., Gore, J. C., LeDoux, J. E., \& Phelps, E. A. (1998). Human amygdala activation during conditioned fear acquisition and extinction: A mixed-trial fMRI study. Neuron, 20, 937-945.

Laufs, H., Krakow, K., Sterzer, P., Eger, E., Beyerle, A., Salek-Haddadi, A., et al. (2003). Electroencephalographic signatures of attentional and cognitive default modes in spontaneous brain activity fluctuations at rest. Proceedings of the National Academy of Sciences of the United States of America, 100, 11053-11058.

Luu, P., \& Tucker, D. M. (2001). Regulating action: Alternating activation of midline frontal and motor cortical networks. Clinical Neurophysiology, 112, 1295-1306

Luu, P., Tucker, D. M., Derryberry, D., Reed, M., \& Poulsen, C. (2003). Electrophysiological responses to errors and feedback in the process of action regulation. Psychological Science, 14, 47-53.

Luu, P., Tucker, D. M., \& Makeig, S. (2004). Frontal midline theta and the errorrelated negativity: Neurophysiological mechanisms of action regulation. Clinical Neurophysiology, 115, 1821-1835.

Makeig, S., Westerfield, M., Jung, T. P., Enghoff, S., Townsend, J., Courchesne, E., et al. (2002). Dynamic brain sources of visual evoked responses. Science, 295, 690-694.

Marco-Pallares, J., Muller, S. V., \& Munte, T. F. (in press). Learning by doing: An fMRI study of feedback-related brain activations. Neuroreport.

McCoy, A. N., Crowley, J. C., Haghighian, G., Dean, H. L., \& Platt, M. L. (2003). Saccade reward signals in posterior cingulate cortex. Neuron, 40, 1031-1040.

Mirenowicz, J., \& Schultz, W. (1994). Importance of unpredictability for reward responses in primate dopamine neurons. Journal of Neurophysiology, 72, 1024-1027.

Montague, P. R., \& Berns, G. S. (2002). Neural economics and the biological substrates of valuation. Neuron, 36, 265-284.

Muller, S. V., Moller, J., Rodriguez-Fornells, A., \& Munte, T. F. (2005). Brain potentials related to self-generated and external information used for performance monitoring. Clinical Neurophysiology, 116, 63-74.

Nieuwenhuis, S., Slagter, H. A., von Geusau, N. J. A., Heslenfeld, D. J., \& Holroyd, C. B. (2005). Knowing good from bad: Differential activation of human cortical areas by positive and negative outcomes. European Journal of Neuroscience, 21, 3161-3168.

Nieuwenhuis, S., Yeung, N., Holroyd, C. B., Schurger, A., \& Cohen, J. D. (2004). Sensitivity of electrophysiological activity from medial frontal cortex to utilitarian and performance feedback. Cerebral Cortex, 14, $741-747$.
O’Doherty, J., Kringelbach, M. L., Rolls, E. T., Hornak, J., \& Andrews, C. (2001). Abstract reward and punishment representations in the human orbitofrontal cortex. Nature Neuroscience, 4, 95-102.

Schultz, W. (2006). Behavioral theories and the neurophysiology of reward. Annual Review of Psychology, 57, 87-115.

Schultz, W., Dayan, P., \& Montague, P. R. (1997). A neural substrate of prediction and reward. Science, 275, 1593-1599.

Schutter, D. J., \& Van Honk, J. (2005). Electrophysiological ratio markers for the balance between reward and punishment. Brain Research Cognitive Brain Research, 24, 685-690.

Shizgal, P. (1997). Neural basis of utility estimation. Current Opinion in Neurology, 7, 198-208.

Snyder, S. M., \& Hall, J. R. (2006). A meta-analysis of quantitative EEG power associated with attention-deficit hyperactivity disorder. Journal of Clinical Neurophysiology, 23, 440-455.

Steriade, M. (2006). Grouping of brain rhythms in corticothalamic systems. Neuroscience, 137, 1087-1106.

Tallon-Baudry, C., Bertrand, O., Delpuech, C., \& Pernier, J. (1997). Oscillatory gamma-band $(30-70 \mathrm{~Hz})$ activity induced by a visual search task in humans. Journal of Neuroscience, 17, 722-734.

Tom, S. M., Fox, C. R., Trepel, C., \& Poldrack, R. A. (2007). The neural basis of loss aversion in decision-making under risk. Science, 315, 515-518.

Tremblay, L., \& Schultz, W. (2000). Reward-related neuronal activity during go-nogo task performance in primate orbitofrontal cortex. Journal of Neurophysiology, 83, 1864-1876.

Trujillo, L. T., \& Allen, J. J. (2007). Theta EEG dynamics of the error-related negativity. Clinical Neurophysiology, 118, 645-668.

Ullsperger, M., \& von Cramon, D. Y. (2001). Subprocesses of performance monitoring: A dissociation of error processing and response competition revealed by event-related fMRI and ERPs. Neuroimage, 14, 1387-1401.

Varela, F., Lachaux, J. P., Rodriguez, E., \& Martinerie, J. (2001). The brainweb: Phase synchronization and large-scale integration. Natural Reviews in Neuroscience, 2, 229-239.

Watanabe, M. (1989). The appropriateness of behavioral responses coded in post-trial activity of primate prefrontal units. Neuroscience Letter, 101, 113-117.

Yacubian, J., Glascher, J., Schroeder, K., Sommer, T., Braus, D. F., \& Buchel, C. (2006). Dissociable systems for gain- and loss-related value predictions and errors of prediction in the human brain. Journal of Neuroscience, 26 , 9530-9537.

Yeung, N., Bogacz, R., Holroyd, C. B., Nieuwenhuis, S., \& Cohen, J. D. (2007). Theta phase resetting and the error-related negativity. Psychophysiology, 44, 39-49.

Yeung, N., Botvinick, M. M., \& Cohen, J. D. (2004). The neural basis of error detection: Conflict monitoring and the error-related negativity. Psychological Review, 111, 931-959.

Yeung, N., \& Sanfey, A. G. (2004). Independent coding of reward magnitude and valence in the human brain. Journal of Neuroscience, 24, 6258-6264.

Yordanova, J., Falkenstein, M., Hohnsbein, J., \& Kolev, V. (2004). Parallel systems of error processing in the brain. Neuroimage, 22, 590-602. 